\title{
Association of perinatal events, epilepsy, and central nervous system trauma with juvenile delinquency
}

Department of Public Health Science and General Practice, University of Oulu, Oulu,

Finland Correspondence to:
Professor Paula Rantakallio, Pepartment of Public Department of Public
Health Science and General Practice, University of Oulu, University SF-90220 Oulu Finland.

Accepted 5 August 1992

\author{
Paula Rantakallio, Markku Koiranen, Jyrki Möttönen
}

\begin{abstract}
The association of perinatal events, childhood epilepsy, and central nervous system trauma with juvenile delinquency was studied prospectively in a geographically defined population of 5966 males in northern Finland. Those who had obtained a criminal record up to the age of 22 years, totalling 355, or $6.0 \%$, were defined as delinquents. The incidence of delinquency was not increased in males with a birth weight less than $2500 \mathrm{~g}$ or greater than $4000 \mathrm{~g}$, preterm births $<37$ weeks' gestation, or those with perinatal brain damage or having epileptic seizures before 14 years of age. The incidence was increased by $6.8 \%$ in the group of males with birth weights less than $3500 \mathrm{~g}$, but not significantly increased after standardisation for a number of social and demographic background variables. The incidence was increased by $10.3 \%$ among the males who had had a central nervous system trauma by the age of 14 years, however, and this factor remained significant when social and demographic factors were standardised by regression analysis, with an odds ratio of 1.9 for all males with a criminal record and an odds ratio of 3.15 for those who had committed a violent crime. Previous central nervous system trauma may be a cause of delinquency, or another possibility is that the type of behaviour pursued by males who are likely to commit a violent crime will expose them more often to accidents which can result in central nervous system trauma.
\end{abstract}

(Arch Dis Child 1992;67:1459-61)

The later development of children with a less favourable perinatal period has been widely investigated with reference to psychomotor, somatic, and mental development, but less interest has been shown in the possible effect of perinatal problems on juvenile delinquency. Causes of delinquency have been sought among social, psychological, and biological factors. ${ }^{12}$ Perinatal problems such as low birth weight and preterm birth may be followed by behavioural difficulties as an expression of brain damage, and central nervous system trauma and epilepsy during later childhood may be suspected to lead to similar difficulties. We analyse here the association of perinatal and childhood disorders with possible somatic consequences in the brain with juvenile delinquency in prospectively collected data on the northern Finland birth cohort for $1966 .^{34}$

\section{Series and methods}

The original series consisted of 12068 pregnant women who gave birth to 12058 liveborn infants in the two northernmost provinces of Finland in 1966, covering $96 \%$ of all births in the area during that year. ${ }^{34}$ Many social and biological characteristics of the mother and family were recorded during the pregnancy, and also perinatal factors such as birth weight, length of gestation, and perinatal mortality and morbidity after the delivery. The social status of the family and health of the children were recorded with another questionnaire when the children were 14 years old, in 1980 and $1981 .{ }^{4} \mathrm{~A}$ family questionnaire was answered by $96 \cdot 1 \%$ of the families, and the data on school performance and general health for most of the other children were collected from the schools. Only 14 children, 1.2 per thousand, had been lost to follow up by that age. In addition, data on the children's health and development were recorded continuously from birth onwards from various morbidity and mortality registers. ${ }^{4}$ Obtainment of a criminal record by the age of 22 years was taken as an indicator of juvenile delinquency. The relevant data were collected from the files maintained by the Ministry of Justice for the population aged over 15 years of age and analysed with the other data early in 1989.

A total of 6007 boys and 5757 girls were alive at the age of 15 years, which, after 75 subjects with an intelligence quotient (IQ) less than 50 had been excluded (they had committed no crimes), ${ }^{5}$ left 5966 males and 5723 females in the series, of whom 355 males $(6.0 \%)$ and 41 females $(0.7 \%)$ had committed at least one crime leading to a criminal record between January 1981 and February 1989. Because of the small number of female offenders, only the data for the males will be considered.

The 355 males were sentenced for 2927 crimes, several sentences often being given concurrently for different crimes-for example, driving an unauthorised motor vehicle without a licence while drunk. The most common crimes were traffic violations, 238 males committing 1097 of these, though 115 of them had also committed crimes of other types. The second most common were crimes involving property, 157 males committing such crimes a total of 1382 times. Violent crimes were taken to include homicides (only three instances), assault, robbery, arson, or violation of domicilary peace. A total of 104 males committed 239 such crimes. Other types of crime were indiscipline, illegal sale or possession of alcohol or narcotics, and sexual crimes, of which 111 males committed 209. The number of males repeating a crime 
was 197. The sentence was conditional in 328 instances and unconditional in 84 . In addition, 117 males were fined. Thus in many instances the same person had conditional and unconditional sentences and still more often were also fined. Cases which result only in a fine do not constitute a criminal record, with an exception of the rare case of the fine being conditional. There was one such case in this series.

The perinatal factors studied were birth weight $<2500 \mathrm{~g},<3500 \mathrm{~g}$, and $>4000 \mathrm{~g}$, preterm births $<37$ full gestational weeks, and perinatal brain damage (table). Birth weight was known for all subjects and gestational age for $5757,96.5 \%$ of the total. ${ }^{4}$ Children were considered to have perinatal brain damage if they had an Apgar score of $\mathbf{0}$ at one minute or less than 5 at 15 minutes, convulsions during the neonatal period, or a diagnosis of asphyxia, brain injury, or intraventricular haemorrhage, but did not have central nervous system malformation, chromosomal aberrations, or hereditary central nervous system degeneration. ${ }^{6}$ Subjects with epilepsy diagnosed up to the age of 14 years ${ }^{7}$ and subjects with central nervous system trauma up to the same age ${ }^{8}$ were also analysed. Epilepsy was considered to have been present if there had been at least one episode of paroxysmal disturbance of consciousness, sensation or movement, primarily cerebral in origin and unassociated with acute febrile episodes. Children with febrile convulsions, blank spells, temper tantrums, and transient convulsions occurring in close relation to central nervous system trauma, central nervous system infection, or some other concurrent disorder were not included. ${ }^{7}$ The diagnoses regarded as central nervous system traumas were trauma to the skull, cranial fracture, cerebral contusion and concussion, vertebral column trauma if there was also injury to the spinal cord, or trauma to the peripheral nerves. Only subjects admitted to hospital and patients attending an outpatient clinic who underwent a special neurological examination and follow up were included. ${ }^{8}$

The associations between health factors and juvenile delinquency were studied by stepwise logistic regression analysis and the relative risk of delinquency was estimated by the odds ratio (OR) and its $95 \%$ confidence interval (CI). Stepwise logistic regression analysis selects the explanatory variables in such a manner that only one of a pair of variables with a high correlation between them is included in the model, for example, of the numerous birthweight variables only that showing the closest association with juvenile delinquency will be included. ${ }^{9}$ Many social and demographic factors affecting the family can function as confounding factors and were therefore included in the analyses. These factors were place of residence (urban/rural) and social class of the father at birth, social mobility, and internal migration up to the age of 14 years, maternal schooling, age, and marital status at birth, parental employment, complete versus incomplete family and number of siblings (all at the age of 14 years), desirability of the pregnancy for the mother, maternal smoking during pregnancy, and paternal smoking during childhood. The non-response to the family questionnaire, $3.9 \%$ of the subjects, was also seen as a confounding variable and was controlled by the logistic regression analysis. These factors have been described more fully elsewhere. ${ }^{10}$

\section{Results}

The table analyses the incidence of delinquency by perinatal events, epilepsy, and central nervous system trauma. Only in the subjects with birth weight $<3500 \mathrm{~g}$ and those with central nervous system trauma is the incidence statistically significantly increased, by $6.8 \%$ for the former group and $10 \cdot 3 \%$ for the latter. Of the 16 subjects with central nervous system trauma and a criminal record, 13 had had concussion, one cerebral contusion, one cerebral contusion and cranial fracture, and one spinal fracture and spinal cord lesion. To study the effect of these biological and health factors on delinquency with the social and demographic background variables standardised, a logistic regression analysis was performed. All the variables presented in the table were included as explanatory variables, together with the social and demographic factors described under methods. The only health factor which had a significant association with delinquency was central nervous system trauma before the age of 14 years, which increased delinquency (OR 1.9, 95\% CI 1.09 to 3.30). The social and demographic factors which increased the risk of delinquency were low social class, downward social mobility, one or no parent in the family, urban dwelling, parental smoking, and non-response to the health questionnaire.

Omission of maternal smoking from the explanatory variables did not alter the resultsthat is, trauma to the central nervous system was significant but not the other health variables.

Number of males with a criminal record by biological and health factors

\begin{tabular}{|c|c|c|c|c|}
\hline $\begin{array}{l}\text { Biological and } \\
\text { health factor }\end{array}$ & $\begin{array}{l}\text { No of subjects } \\
\text { with criminal record }\end{array}$ & All males & $\begin{array}{l}\text { Incidence of } \\
\text { criminal record (\%) }\end{array}$ & $\begin{array}{l}\text { Difference with } \\
\text { respect to others, } \\
\text { by } \chi^{2} \text { test } \\
(p \text { value })\end{array}$ \\
\hline $\begin{array}{l}\text { Birth weight }<2500 \mathrm{~g} \\
\text { Birth weight }<3500 \mathrm{~g} \\
\text { Birth weight }>4000 \mathrm{~g} \\
\text { Preterm birth }<37 \text { weeks' gestation* } \\
\text { Firstborn infant } \\
\text { Born 4th or later in family } \\
\text { Perinatal brain damage } \\
\text { Epilepsy } \\
\text { Trauma to central nervous system } \\
\text { All subjects }\end{array}$ & $\begin{array}{r}12 \\
177 \\
61 \\
30 \\
119 \\
66 \\
3 \\
5 \\
16 \\
16 \\
355\end{array}$ & $\begin{array}{r}178 \\
2611 \\
1058 \\
502 \\
1921 \\
1052 \\
75 \\
95 \\
155 \\
5966\end{array}$ & $\begin{array}{r}6 \cdot 7 \\
6 \cdot 8 \\
5 \cdot 8 \\
6 \cdot 0 \\
6 \cdot 2 \\
6 \cdot 0 \\
4 \cdot 0 \\
5 \cdot 3 \\
10 \cdot 3 \\
6 \cdot 0\end{array}$ & $\begin{array}{l}0.651 \\
0.017 \\
0.778 \\
0.972 \\
0.598 \\
0.929 \\
0.472 \\
0.775 \\
0.020\end{array}$ \\
\hline
\end{tabular}

Known for 5757 males. 
As brain damage has been suspected as a particular cause of violent crimes, two further logistic regression analyses were performed: on males who committed a violent crime and on males who committed some other type of crime. Central nervous system trauma increased the risk in the former analysis (OR 3.15, 95\% CI 1.37 to $7 \cdot 26$ ) but not significantly so in the latter (OR $1 \cdot 47,95 \%$ CI 0.72 to $2 \cdot 98$ ). In neither of these analyses was any other health factor significant.

\section{Discussion}

Roughly $10 \%$ of Finnish males will acquire a criminal record during their lifetime. The main type of crime among males who are sentenced for the first time after adolescence is financial impropriety-for example, infringement of bankruptcy laws or tax evasion. Thus our series with a $6 \%$ rate of criminal records includes a substantial number of subjects in this cohort who will commit crimes other than financial crimes. Nevertheless some of the cohort members had committed only a minor crime and will never do so again, but these subjects can be identified only by further follow up surveys.

The boys with a low IQ $(<50)$ were excluded because they were over represented among the subjects with epilepsy and those with perinatal brain damage and can be taken as less 'capable' of juvenile delinquency as measured by a criminal record and are therefore potential confounding elements. Nevertheless, the incidence of delinquency was not increased either in the subjects with epilepsy or in those with perinatal brain damage (table). The incidence of delinquency was statistically significantly increased among the males with a birth weight less than $3500 \mathrm{~g}$, but when the background variables were standardised by logistic regression analysis this significance disappeared, because lower birth weight has an association with factors such as low social status and maternal smoking during pregnancy. A positive association between unfavourable perinatal events and delinquency has been found in some series ${ }^{11} 12$ but not in another. ${ }^{13} 14$ In our series there was clearly no such association.

The association between epilepsy and delinquency, especially that seen in violent crimes, has been widely discussed ${ }^{15-17}$ without any clear agreement being reached. Our definition of epilepsy was broad, and many of these males were probably no longer having seizures during adolescence, but it is evident that the group having epileptic seizures during childhood have no particular risk of juvenile delinquency.
Central nervous system trauma was the only health factor which had a statistically significant association with delinquency, especially with that seen in violent crimes, and it remained significant when the data were standardised for many of the background variables. Previous retrospective Finnish surveys have not found such an association. ${ }^{16} 18$ This relation may be causal, but another possibility is that the type of behaviour pursued by males who are likely to commit a violent crime will expose them more often to accidents which can result in central nervous system trauma.

The causes of juvenile delinquency are a complex matter closely related to childhood and adolescent psychiatry, sociology, psychology, neurophysiology, and criminology. We cannot go into the theories and findings in those fields here, but the results show clearly that whatever the reasons for delinquency, they are not mediated through perinatal disorders or childhood epilepsy.

This study was supported by grants from the Academy of Finland.

1 Hollin C. Psychology and crime. An introduction to criminological psychology. London: Routledge, 1989.

2 Pitts J. The politics of juvenile crime. London: Sage, 1988

Rantakallio P. Groups at risk in low birth weight infants and perinatal mortality. Acta Paediatr Scand Suppl 1969;193: 1-71.

4 Rantakallio $P$. The longitudinal study of the Northern Finland birth cohort of 1966. Paediatr Perinat Epidemiol 1988;2: 59-88.

5 Rantakallio P, vonWendt L. Mental retardation and subnormality in a birth cohort of 12000 children in Northern Finland. American Fournal of Mental Deficiency 1986;90: 380-7.

6 Rantakallio P, vonWendt L, Koivu M. Prognosis of perinatal brain damage: a prospective study of a one year birth cohort of 12000 children. Early Hum Dev 1987;15:75-84.

7 von Wendt L, Rantakallio P, Saukkonen A-L, Mäkinen H. Epilepsy and associated handicaps in a 1 year birth cohort Epilepsy and associated handicaps in a 1 year birth co
in Northern Finland. Eur $\mathcal{J}$ Pediatr 1985; 144:149-51.

8 Rantakallio $P$, von Wendt $L$. Trauma to the nervous system and its sequelae in a one-year birth cohort followed up to the age of 14 years. $f$ Epidemiol Community Health 1985;39: 353-6.

9 Engelman L. Stepwise logistic regression. In: Dixon WJ, ed. $B M D P$ statistical software manual. Vol 2. Berkeley: University of California Press, 1990:1013-46.

10 Rantakallio P, Läärä E, Isohanni M, Moilanen I. Maternal smoking during pregnancy and delinquency of the offspring - an association without causation? Int f Epidemiol (in press).

11 Pasamanick B, Rogers ME, Lilienfeld AM. Pregnancy experience and the development of behavior disorder in children. Am f Psychol 1956;112:613-8.

12 Stott DH. Evidence for a congenital factor in delinquency and maladjustment. Am $\mathcal{F}$ Psychol 1962;118:781-94.

13 West DJ. Present conduct and future delinquency. London: West DJ. Present conduct and future
Heinemann Educational Books, 1969.

14 West DJ, Farrington DP. Who becomes delinquent? London: Heinemann Educational Books, 1973.

15 Mark VH, Ervin FR. Violence and the brain. New York: Harper and Row, 1970.

16 Mattila J. Alttiudesta syyllistyä toistamiseen väkivaltarikokseen On proneness to repeat a violent offence [English abstract]. Helsinki: Psychiatria Fennica, 1988. (Monograph series.)

17 Pincus JH. Can violence be a manifestation of epilepsy? Neurology 1980;30:304-7.

18 Virkkunen $M$, Nuutila $A$, Huusko $S$. Brain injury and criminality. A retrospective study. Diseases of the Nervous System 1977;38:907-8. 